Artigo recebido em:

06.07.2016

Aprovado em:

08.08.2016

Ivan Paganotti graduado em Jornalismo, Mestre e

Doutor em Ciências da Comunicação todos títulos obtidos na Universidade de São Paulo; é professor no Curso de Jornalismo do Colégio Stockler e nos Cursos de

Pós-graduação (lato sensu) em Gestão Integrada da Comunicação Digital para Ambientes Corporativos (Digicorp-USP) e Pós-graduação (lato sensu) em Assessoria de Comunicação e Mídias Sociais, da Universidade Anhembi-Morumbi.ivanpaganotti@ gmail.com
Estudos em Jornalismo e Mídia Vol. 13 No 1 Janeiro a Junho de 2016, ISSNe 1984-6924

\title{
Ondas econômicas além das medidas: incomparáveis dívidas e riquezas brasileiras nas páginas do New York Times $^{1}$
}

Ivan Paganotti

\section{Resumo}

A cobertura da grande mídia internacional pode apresentar alinhamento liberal ao tratar de economias emergentes como a brasileira. Para avaliar a manutenção do receituário neoliberal como fonte das ponderações econômicas midiáticas, é possível balizar a análise de reportagens publicadas por um dos maiores representantes da grande mídia internacional - o diário norte-americano The New York Times e seu ex-correspondente Larry Rohter - em relação às propostas de reforma econômica e abertura de mercados, defendidas pelo chamado "Consenso de Washington". Este artigo pretende avaliar como a cobertura econômica do New York Times, em um longo período de tempo (de 1985 a 2009) transformou sua avaliação sobre o Brasil, reposicionando o país entre o polo negativo e o positivo das comparações em índices econômicos.

\section{Palavra-chave:}

correspondentes internacionais; jornalismo; economia.

\begin{abstract}
It is possible that international media coverage can have a liberal approach when dealing with an emerging economy such as Brazil. This paper evaluates how the North-American correspondent Larry Rohter, from The New York Times, based his journalistic economic analysis on a neoliberal prescription. This newspaper can represent how a big international media debates and suggests economic reforms that involve open markets - the so-called "Washington Consensus". This article analyzes how the economic coverage of The New York Times, during the long period of mid1980 until the end of the first decade of the 21st century, has shifted its evaluation on the Brazilian economy, repositioning the country between a negative pole to a more positive one, when comparing economic indexes.
\end{abstract}

Keywords:

foreign correspondents, journalism; economy.
${ }^{1}$ Uma versão preliminar desse trabalho foi apresentada no IX Encontro Nacional de Pesquisadores em Jornalismo da SBPJor. 
J á é clássica a definição de Herman e McChesney sobre os meios de comunicação globais agirem como verdadeiros "missionários do capitalismo corporativo" (HERMAN só pregam um evangelho que defende os princípios da abertura das economias de mercado, mas também são eles mesmos definidos como grandes conglomerados multinacionais, que lucram com a venda da notícia como mercadoria (HABERMAS, 2003, p. 35).

$\mathrm{Na}$ linha de frente do processo de "conversão" ao evangelho capitalista, os correspondentes internacionais constroem seus relatos de viagem em forma de reportagens que trazem informações sobre as dificuldades em catequizar os bárbaros locais de forma a levá-los à salvação do prometido paraíso liberal (HIGGINS, 2006, p. 190) - assim como apresentam as riquezas que podem ser exploradas e funcionam como recompensa para os que se sentirem atraídos a essa empreita neocolonial (PRATT, 1999, p. 69).

No Brasil, são imagens com fundamentos históricos na visão de uma terra iluminada pelo resplandecer de pedras e metais minerados e dulcificada pelos engenhos do Nordeste, antepassados da antiga corrida pela tríade café/borracha/ laranja (HOLANDA, 2007, p. 41) e, atualmente, por gado, soja e petróleo. Como apontado por Holanda, a caça colonial aos tesouros maravilhosos nutridos pelas terras brasileiras seguia também o imaginário fertilizado por imagens de outros tempos anteriores, como as esmeraldas edênicas (Id., ibid., p. 70), ou de outros lugares vizinhos, como o desejo de se encontrar minas como as peruanas em territórios brasileiros (Id., ibid., p. 103). A persistência das imagens históricas de um território colorido por especiarias e nomeado por um produto de extrativismo exportado até sua quase extinção o pau-brasil - explica a predominância econômica do atual noticiário internacional sobre o Brasil: de acordo com pesquisa divulgada em 2010 sobre a imagem do Brasil em 15 jornais internacionais de grande porte, quase $80 \%$ da cobertura brasileira envolve temas econômicos, como "empresas e executivos do Brasil" (20,25\%), "investimentos no país" (16,56\%), "comércio exterior" (9,36\%) e outros temas relacionados (CRESPO, 2010).

Diversas pesquisas anteriores já apontaram com precisão que grandes veículos da mídia internacional partem de um viés liberal para medir - e, frequentemente, criticar - medidas econômicas de países emergentes como o Brasil (DOTA, 2004 , p. 15). Tanto trabalhos quantitativos (GROSECLOSE; MILYO, 2004) quanto artigos analíticos (HERMAN, 1998) apontam semelhante aproximação de grandes diários internacionais, como o New York Times, com interesses comerciais de grandes empresas norte-americanas. O próprio ombudsman desse diário nova-iorquino acata, de certa forma, a classificação do jornal como um veículo "liberal" (OKRENT, 2004) - considerando o sentido norte-americano do termo, que ultrapassa as medidas econômicas e engloba também as reformas sociais - e também seu público reconhece um viés liberal nas páginas do NYT (RASMUSSEN REPORTS, 2007).

Devido à grande atenção que a bibliografia em jornalismo dedica ao New York Times, considerado um grande modelo entre os maiores diários internacionais, é convidativo tomar esse jornal como representativo não só das práticas midiáticas que inspira, mas também dos discursos que promove e defende. Mas ainda é possível apontar um viés econômico liberal no New York Times? A crise mundial da última década afetou de que forma sua cobertura sobre temas econômicos? E, mais importante, como as representações brasileiras nas páginas dos grandes diários internacionais se transformaram, considerando as grandes mudanças econômicas das últimas décadas?

Para responder essas perguntas, um ponto de partida interessante é avaliar a cobertura do correspondente internacio- 
nal Larry Rohter, do NYT, não só durante o período em que o jornalista atuou como chefe da sucursal carioca do diário norte-americano (de 1998 a 2007), mas também em todo o período anterior, quando o Brasil surgia em seus relatos sobre a América Latina como um mau exemplo devido à crise da dívida e superinflação dos anos 1980. Os textos de Rohter podem agir como uma bússola que oscila tanto em relação aos deslocamentos da paisagem brasileira que pretende retratar, como também devido aos novos vieses que norteiam a avaliação econômica de seu jornal. Desde o início, a cobertura brasileira de Rohter no NYT sempre esteve entrelaçada com as ondulações dos mercados e os naufrágios de planos econômicos:

Adding to a sense of crisis here, interest rates soared and investors continued to withdraw money from Brazil. The International Monetary Fund and senior Clinton Administration officials said they had warned Brazil's President that his Government was unlikely to be able to prevent the currency, the real, from sinking below the exchange rate announced on Wednesday. (...) Government's defense of the currency made Brazilian exports more expensive than those of many competitors, and made imports artificially cheap, encouraging Brazilians to binge on consumer goods and foreign travel. That, in turn, accelerated the drain of reserves of foreign currency, adding to the pressure for a devaluation of the real. (...)

Critics, though, argue that Brazil's currency is still overvalued by as much as 30 percent, and that President Francisco Henrique Cardoso and his advisers will only waste additional reserves and prolong the country's crisis by attempting to defend the new rate. Many of those critics maintain that Brazil can only resolve its troubles by allowing the market to determine the currency's true value. (...) The nation's Congress on Wednesday approved four measures that will add more than $\$ 3$ billion to Government revenue, helping to reduce the budget deficit and help satisfy the I.M.F. ${ }^{2}$

O trecho apresenta uma visão típica de um receituário idealizado nos anos 1990 que dominou a cobertura econômica e, aos poucos, também as políticas governamentais. Sem exigir fontes, uma explicação apresenta um aparente consenso, sustentado pelo relato do repórter sobre as causas da crise da desvalorização. A concatenação de pontos pacíficos, como esse, tenta também ecoar, com a mesma legitimidade, o diagnóstico que aponta a ineficiência das medidas paliativas: "críticos" apontam que as ações adotadas pelo Brasil não vão funcionar; é um "desperdício" lutar pela "defesa" do Real, pois a desvalorização é tomada como fato já consumado. Posteriormente, os mesmos "críticos" apontam outra receita e quem deve ter a legitimidade para aplicá-la: o "Brasil só pode resolver seus problemas ao permitir que o mercado determine o verdadeiro valor de câmbio". Assim, cortes são feitos para aplacar a fúria dos especuladores, como um ritual de sacrifício de virgens para acalmar um deus que só é visto e temido nos momentos de ira vulcânica: essas medidas vão "ajudar a reduzir o déficit orçamentário e ajudar a satisfazer o FMI" - o Fundo Monetário Internacional.

Após o sinal amarelo do alerta, identifica-se a causa do problema, que deve parar; segue-se um sinal verde para novas medidas receitadas. $\mathrm{Ou}$, retomando o imaginário médico-científico, os sintomas da crise surgem quando a prevenção falha, levando a um diagnóstico que aponta a ineficiência do tratamento paliativo local, impondo um receituário mais amargo e operações mais intrusivas; a cura da crise só pode ser alcançada a partir do sofrimento do paciente, que não deve participar ativamente da escolha de seu tratamento, sugerido por observadores externos interessados na recuperação de seus investimentos. Nesse
${ }^{2}$ ROHTER, Larry. "International Business; Crisis is deepening in Brazil Markets". The New York Times (NYT), 15/01/1999. Tradução do autor: "Somando-se ao sabor de crise, taxas de juros subirame investidores continuaram a retirar seu dinheiro do Brasil. $O$ Fundo Monetário Internacional e oficiais da Administração Clinton dizem ter avisado o Presidente do Brasil que seu governo provavelmente não poderia prevenir a moeda, o real, de afundar abaixo da taxa de câmbio anunciada na quarta-feira. (...) A defesa governamental da moeda $\mathrm{fez}$ as exportações brasileiras serem mais caras do que muitos dos competidores, e fez as importações ficarem artificialmente mais baratas, levando os brasileiros a comprar mais produtos importados e viajar para o exterior. Isso, em troca, acelerou o esvaziamento da reserva de moeda estrangeira, o que adicionou à pressão para a desvalorização do real. (...) Os críticos, porém, argumentam que a moeda brasileira ainda está até $30 \%$ supervalorizada, e que o Presidente Fernando Henrique Cardoso e seus conselheiros vão apenas gastar reservas adicionais e prolongar a crise do país ao tentar defender essa nova taxa. Muitos desses críticos dizem que o Brasil pode resolver esses problemas apenas permitindo que o mercado determine o verdadeiro valor da sua moeda. (...) O Congresso Nacional, na quarta-feira, aprovou quatro medidas que adicionarão mais de \$3 bilhões para a receita do Governo, ajudando a reduzir o déficit de orçamento e a satisfazer o FMI". 
${ }^{3}$ ROHTER, Larry.

"Mexican Calls for Debt Flexibility". NYT, 02/09/1987. Tradução do autor: "México, que deve mais de US\$ 100 bilhões para credores estrangeiros, tem a segunda maior dívida entre os países em desenvolvimento, atrás somente do Brasil".

${ }^{4}$ Os gráficos a seguir (2 e 3) envolvem 161 textos, pois medidas comparativas não estavam presentes em todos os textos em que o Brasil é citado ou que tratavam majoritariamente sobre o país. sentido, o presente artigo procura avaliar como esse receituário foi recomendado, acompanhado e transformado no período em que o correspondente internacional Larry Rohter passou no Brasil, das crises da dívida e da hiperinflação dos anos 1980 até o novo modelo de crescimento econômico da primeira década do século XXI.

\section{Medidas para desafios incomparáveis}

Décadas antes do relato acima o cenário econômico brasileiro que surgia nos relatos de Rohter era ainda pior. Antes de poder ascender ao caso clínico em recuperação de crises, o país parecia um paciente terminal, desenganado - sua doença era tão grave que era até tomado como parâmetro negativo de comparação internacional.

No período anterior à chefia da sucursal carioca do NYT, Rohter produzia textos sobre a América Central e, mesmo depois, o correspondente continuava cobrindo outros países vizinhos na América do Sul. Com isso, considerando-se somente os textos que mencionam o Brasil (727 artigos) e excluindo os textos que tratam exclusivamente de outras nações (mais de 1800), em diversos períodos a cobertura do correspondente não estava voltada majoritariamente ao país, como pode ser visto no Gráfico 1: dos 727 textos sobre o Brasil, 567 (78\%) tratavam majoritariamente do país; já em 160 artigos (22\%), o país era somente citado em relatos sobre outras regiões.

Gráfico 1. Artigos majoritariamente sobre o Brasil e textos que somente citam o país, por ano.

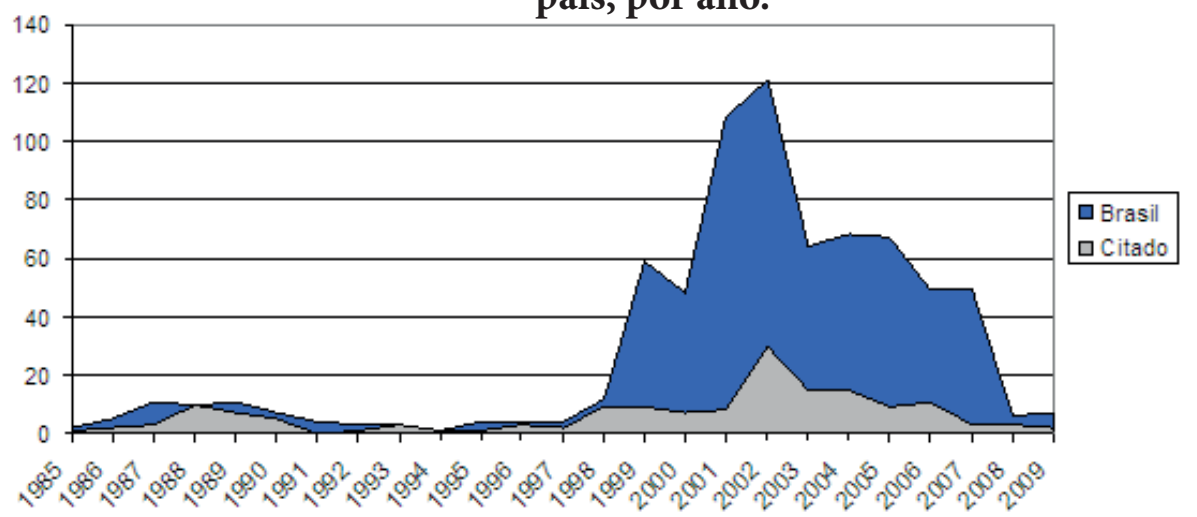


Gráfico 2. Elementos de comparação de superioridade, igualdade ou inferioridade.

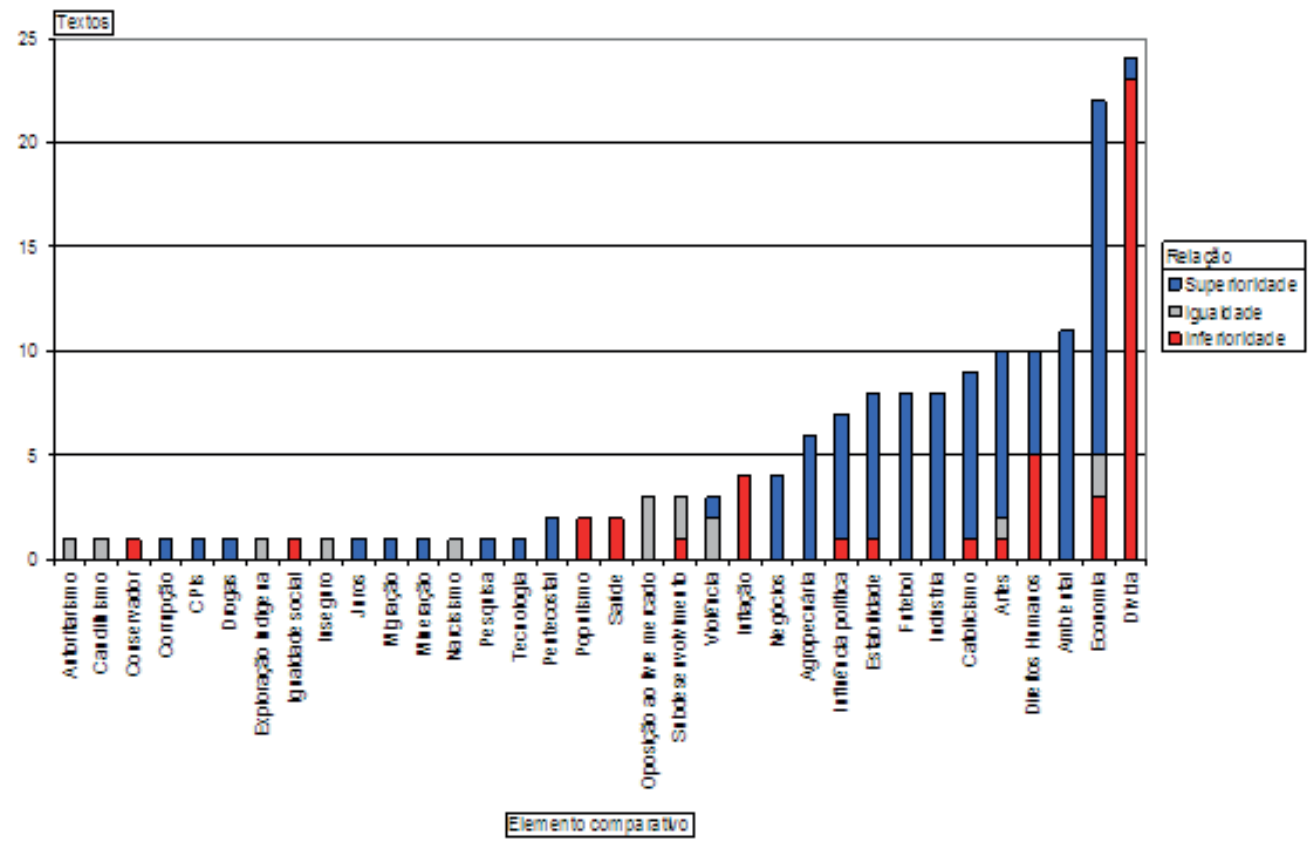

Entre os elementos comparativos, o endividamento nacional era apontado negativamente em 23 textos, como no exemplo anterior. Outro fator correlato que apontava inferioridade do país era a inflação, mencionada 4 vezes, todas negativamente:

Those measures were instantly disputed in a country that does not have the same tradition of high inflation as other Latin American countries, such as Brazil, Argentina or Bolivia. Though inflation has soared to triple digits the last two years, throughout the 1960's and into the early 70's, it averaged less than 3 percent a year. ${ }^{5}$

O trecho parte da análise sobre a crescente inflação mexicana, contraposta com os níveis endêmicos brasileiros, acompanhada por outros exemplos negativos na Argentina e Bolívia. O efeito é desolador: se nesse lugar de onde o correspondente reporta a crise já é grave o suficiente para justificar uma análise econômica tão desfavorável (como eram os relatos mexicanos no final dos anos 1980), imagina-se a situação catastrófica nos outros lugares tomados para comparação de inferioridade. Os dois trechos também apontam uma tendência nas reportagens de Rohter: as comparações são feitas de forma absoluta, e não entre grandezas relativas. Assim, a dívida e a inflação mexicana não são tão graves quanto as do Brasil, porém somente os índices mexicanos são apontados, o que não permite comparar o quanto a situação brasileira estaria pior. $\mathrm{O}$ resultado é ainda mais angustiante: esses índices podem não ser incomparáveis, visto que ainda é possível determinar quem está pior; porém, a situação nos outros lugares comparados negativamente deve estar além das medidas, já que não se mesura o cenário nesses outros lugares

Gráfico 3. Comparação de superioridade, igualdade ou inferioridade nos anos.

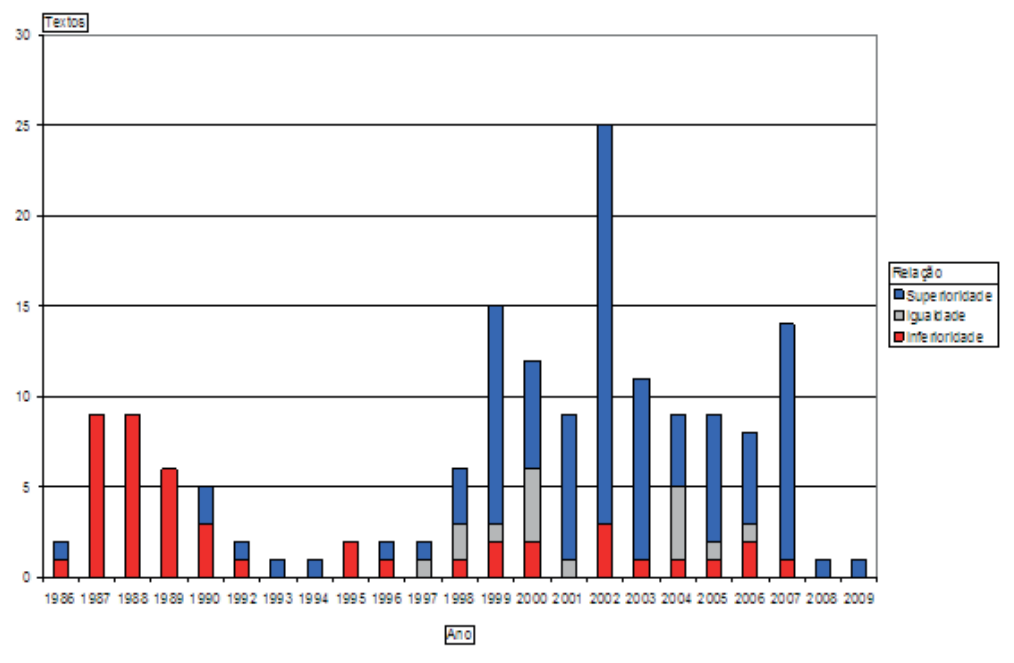


${ }^{6}$ ROHTER, Larry. "Argentina Paying Heavily for Squandering Blessings". NYT, 08/02/2002.

Tradução do autor:

"Ao invés de investir em tecnologia e ciência, o esforço foi posto em treinar psiquiatras e advogados porque era mais fácil e não exigia tantas

despesas', disse Aguinis, um ex-ministro da cultura. 'Nós tínhamos o mesmo nível de talento humano que o Brasil, se não melhor. Mas eles que acabaram industrializando, nós não, porque eles estavam dispostos a gastar dinheiro em equipamento e laboratórios para treinar engenheiros e químicos"”.

${ }^{7}$ Tradução do autor: "O novo modelo argentino: seu antigo rival, Brasil".

${ }^{8}$ ROHTER, Larry.

“Argentina's New

Role Model: Its Old

Rival, Brazil". NYT,

05/08/2002. Tradução

do autor: "Argentina e

Brasil sempre foram o casal estranho da América do Sul, tão diferentes

e desconfiados um do outro quanto a França e a Alemanha uma vez foram. (...) Desde assumir no governo em janeiro,

o presidente Eduardo

Duhalde tem repetidamente apontado o Brasil como uma economia em desenvolvimento bem-sucedida, particularmente desde sua decisão em 1999 de permitir que

o valor de seu câmbio caísse ao invés de atrelar seu índice ao dólar".

${ }^{9}$ ROHTER, Larry.

"Tiptoeing Leftward: Uruguayan Victor's Moment of Truth". NYT, 02/11/2004. Tradução do autor: "seguir o exemplo de Lula" / "políticas amigáveis ao mercado que ele tem desejado". tomados como comparação. Entretanto, especialmente em períodos mais recentes, a tendência negativa inverteu-se, como pode ser notado no Gráfico 3. Nas reportagens de Rohter, o Brasil ainda é tomado mais como ponto positivo em 100 textos, ou $62,1 \%$ das 161 comparações, ante 46 relações de inferioridade $(28,6 \%)$ e 15 de igualdade $(9,3 \%)$.

O período inicial de inferioridade, no final dos anos 1980, condiz tanto com o período de crise da dívida e de recessão econômica quanto com o momento anterior à chefia da sucursal carioca do NYT por Rohter: assim, o Brasil era somente tangenciado em sua cobertura, antes de 1998, e muitas vezes esses pontos de aproximação eram feitos por meio de comparações de inferioridade, como as analisadas anteriormente, determinadas pelo desanimador cenário econômico na época. Após 1998, há uma predominância de comparações positivas, ainda que crises econômicas tenham abatido o país, especialmente em 1999, durante a desvalorização do real, e em 2002, com a eleição de Lula. Porém, os números de comparações negativas não chegaram aos mesmos níveis anteriores, e ainda são relativizados por uma maioria de comparações positivas. Isso aponta que, além da própria situação brasileira na época (que nem de perto se aproximava da crise do final dos anos 1980), a proximidade do correspondente permite uma diversificação de temas comparados e mais posicionamentos de superioridade, como no trecho a seguir:

'Instead of investing in technology and science, the effort was put into training psychiatrists and lawyers because that was easier and didn't require as much expense." said Mr. Aguinis, a former minister of culture. "We had the same level of human talent as Brazil, if not better. But they were the ones who ended up industrializing, not us, because they were willing to spend money on equipment and laboratories to train engineers and chemists."
Essa passagem inverte um elemento comparativo inicialmente de igualdade ou inferioridade para o Brasil para revelar a posterior superioridade industrial brasileira, na avaliação de uma fonte argentina que tenta explicar porque o Brasil superou as crises na virada do milênio melhor do que seus vizinhos. Como visto no Gráfico 3, atualmente o Brasil parece ter saído da sombria área negativa da inferioridade em comparações desabonadoras como a dívida e a inflação, deixando também o leito da vítima, um mero alvo de medidas que seguem receituários internacionais. Textos mais recentes de Rohter representam o país no polo positivo, como um modelo atraente a ser seguido e como um formulador de soluções próprias. Em uma reportagem com o provocativo título "Argentina's New Role Model: Its Old Rival, Brazil", Rohter aponta como a antiga competitividade foi superada por um posicionamento de valorização do irmão maior brasileiro:

Argentina and Brazil have always been South America's odd couple, as different from and as suspicious of each other as the French and the Germans once were. [...] Since taking office in January, President Eduardo Duhalde has repeatedly pointed to Brazil as a successful developing economy, particularly since its decision in 1999 to allow the value of its currency to decrease instead of keeping it pegged to the dollar. ${ }^{8}$

As avaliações argentinas posicionam duplamente o Brasil como um modelo a ser seguido. A primeira medida brasileira que merece louvor presidencial foi a "decisão" bem-sucedida de seguir o receituário amargo da desvalorização cambial, um caminho que começava a ser trilhado também pela Argentina na época da reportagem. O futuro de outro vizinho também é representado a partir do mesmo modelo brasileiro, representado, nas palavras do ministro uruguaio da economia Danilo Astori, no plano de 
"follow the example of Lula", contextualizado por Rohter como as "market-friendly policies he has pursued" . Porém, fica evidente como o exemplo brasileiro é adotado, em ambos os casos, como um símbolo das mesmas medidas de contenção fiscal e abertura de mercados, ainda que de forma mais moderada:

The promise to follow Brazil's conservative fiscal example has reassured many of the money managers who feared the worst when Mr. da Silva was elected two years ago. "Everything is normal," one banker said. "Nobody is nervous, and money isn't leaving the country." ${ }^{10}$

Com isso, os textos apresentam o Brasil como um novo modelo enquanto evidenciam que, na verdade, o caminho brasileiro passa pelos mesmos passos do prognóstico do "FMI, Banco Mundial e Washington", como apontado anteriormente $^{11}$. Porém, essa contradição funciona para mostrar como o Brasil converteu-se de economia moribunda a paciente-modelo, fornecendo para os países vizinhos um exemplo mais flexível, menos distante - e mais atrativo, na avaliação argentina - do que as demandas rígidas e, por vezes, inacessíveis do receituário de "conservadorismo fiscal" como ditado por organismos internacionais ao norte do equador. Assim, o texto constrói uma representação do país como um mediador: mais uma vez distancia o discurso de seus vizinhos da aproximação perigosa com o ideário liberal, enquanto alinha suas práticas com o mesmo receituário antigo. Os textos apontam mudanças, mas reafirmam as expectativas anteriores - principalmente de agentes financeiros como o "banqueiro" citado no último artigo.

\section{Receita consensual, entre Washington e Brasília}

Retomando o Gráfico 2, salta aos olhos como os principais elementos de comparação em que o Brasil detém uma posição de superioridade também envolvem temas como a economia, agropecuária, estabilidade, indústria e negócios, além de outros orgulhos nacionais subjetivos, como futebol e artes, e elementos de grandiosidade objetiva, como o número de católicos brasileiros e diversos dados relativos à biodiversidade, tamanho ou importância ambiental de biomas como a Amazônia. Juntamente com a inferioridade no endividamento e na inflação, os temas econômicos somam sete dos treze termos de comparação mais citados. Talvez isso se deva a uma característica própria dos índices econômicos, como se a mensuração e a criação de índices comparativos, própria da gestão financeira, determinasse também possibilidades de comparação entre esses critérios devido à publicação e ao acesso de estatísticas de diversos países na composição dos relatos jornalísticos.

Por outro lado, é importante considerar o duplo sentido do termo "medida", adotado nesta análise: pode significar tanto "mensuração" e "comparação" quanto uma "atitude", como as ações brasileiras tomadas como exemplo por seus vizinhos ou as reformas que seguem as receitas dos organismos internacionais como o FMI e Banco Mundial. Esse duplo sentido também é importante ao considerar a mudança da polarização brasileira entre a inferioridade e a superioridade: a nova "medida" com que são mensuradas as "ações" brasileiras não se deve somente aos fatores apontados anteriormente, como a aproximação do correspondente e a melhoria econômica do cenário nacional; também faz parte da própria reformulação pela qual o ideário liberal passou nas páginas do NYT e, em especial, nos relatos de Rohter:

Secretary of the Treasury Nicholas F. Brady urged Argentina, Brazil and other debtors "to do what Mexico did: bite the bullet, make the tough choices, put on economic programs that open up markets, reduce tariffs and barriers." But many doubt whether these sacrifices are worth the limited relief Washington has thus far DOI: 10.5007/1984-6924.2016v13n1p131
${ }^{10}$ Id., ibid. Tradução do autor: "A promessa de seguir o exemplo de conservadorismo fiscal brasileiro assegurou muitos dos gerenciadores financeiros que temiam o pior quando Lula foi eleito dois anos atrás. 'Tudo está normal', um banqueiro disse. 'Ninguém está nervoso, e o dinheiro não está deixando o país".

${ }^{11}$ ROHTER, Larry. "With New Chief, Uruguay Veers Left, in a Latin Pattern". NYT, 01/03/2005. 
${ }^{12}$ ROHTER, Larry.

"THE WORLD; Central

America Goes Its Own Way”. NYT, 13/08/1989.

Tradução do autor: "O secretário do tesouro Nicholas F. Brady recomendou que Argentina, Brasil e outros endividados 'façam o que o México fez: apertem os cintos, façam as escolhas difíceis, abram seus mercados, reduzam tarifas e barreiras'. Mas muitas dúvidas sobre se esses sacrifícios valem a ajuda limitada oferecida até agora por Washington. 'Se esse é o melhor acordo que o pupilo de ouro consegue', um diplomata latino-americano disse aqui, 'então não há muita esperança para o resto de nós”". offered.

"If this is the best deal that the prize pupil can get," a Latin American diplomat here said, "then there is not an awful lot of hope for the rest of us." 12

O trecho acima é representativo da forma como um ideário internacional cristalizado era reproduzido em diversas reportagens de Rohter - e também por tomadores de decisão latino-americanos que seguiam recomendações de representantes da política econômica de Washington, com o famoso secretário do Tesouro Nicholas Brady. A passagem também mostra como, antes do Brasil, outros países latino-americanos faziam o papel de paciente-modelo ou "pupilo de ouro", como o México, ao adotar a recomendação internacional segundo um receituário de princípios e práticas liberais como a "abertura dos mercados e a redução de tarifas e barreiras", as "decisões difíceis" recomendadas por Brady.

Também conhecido como "Consenso de Washington", esse receituário neoliberal apresenta uma lista de ações que

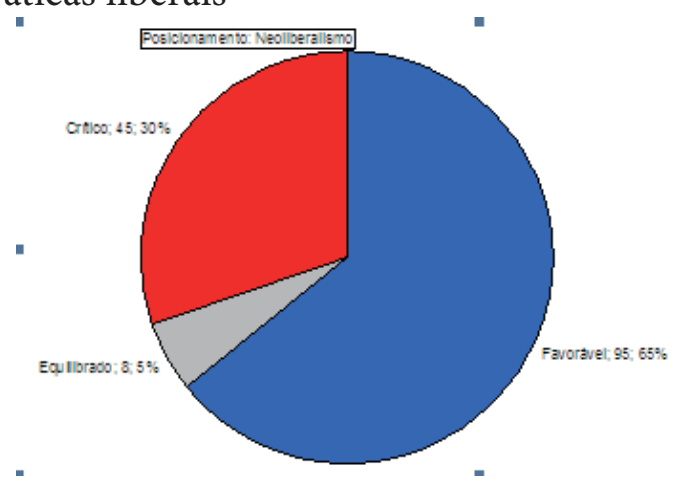

governos deveriam seguir como mandamentos bíblicos para receber os benefícios comerciais da abertura liberal. Em primeiro lugar, exige-se que o estado diminua sua participação indevida e ineficiente na economia com cortes fiscais, contenção de gastos governamentais e redução de incentivos, barreiras e subsídios. Essas medidas de abertura comercial devem também permitir que as empresas atuem em novas áreas por meio de privatizações e da liberalização de setores protegidos, ao mesmo tempo em que se fornecem garantias para o estabelecimento de empresas multinacionais, fortalecendo os direitos de propriedade (WILLIAMSON, 1997).

Considerando a forma como as reportagens de Rohter apresentavam essas
Gráfico 4. Posicionamento (crítico, favorável ou equilibrado) sobre neoliberalismo.

receitas e outros temas do ideário liberal, foi possível identificar quando os textos tendiam a aproximar-se dessas recomendações, como um modelo a ser seguido a partir da representação do trecho acima, ou ao distanciar-se desse "consenso" (KUCINSKI, 2000, p. 189), apontando suas limitações, custos ou inadequações. Dos 727 textos sobre o Brasil publicados por Rohter no NYT, 148 (20,4\%) mencionavam medidas como as citadas acima; desses textos, 95 reportagens (65\%) apresentavam um posicionamento favorável às práticas neoliberais, $45(30 \%)$ criticavam essas medidas e 8 artigos (5\%) ponderavam argumentos de forma equilibrada, como representado no Gráfico 4:

Como visto na introdução desta pesquisa, o alinhamento liberal da cobertura do New York Times já foi apontado por autores como Herman (1998), Groseclose e Milyo (2004), além de assumido pelo próprio ombudsman do jornal (OKRENT, 2004) e reconhecido pelo seu público (RASMUSSEN REPORTS, 2007). A abordagem negativa da cobertura econômica brasileira de Rohter já foi identificada por Dota (2004, p. 15), porém, em períodos mais recentes, o receituário liberal antigamente favorecido tem passado por um escrutínio mais crítico nas reportagens do correspondente sobre o Brasil. Como o Gráfico 5 aponta, entre os anos de 1987 e 2002 o noticiário foi ponderadamente mais favorável ao receituário neoliberal, com 80 textos positivos $(79,2 \%$ dos 101 
textos desse período), contra somente 19 críticos $(18,8 \%)$ e 2 equilibrados $(1,9 \%)$; porém, de 2003 a 2008, a tendência dos textos de Rohter passou a ser ligeiramente mais crítica, com 26 textos (55,3\% das 47 reportagens no período) que representavam pontos de vista contrários às medidas neoliberais, além de mais visões equilibradas (6 textos, ou $12,7 \%$ ) e menos favoráveis (somente 15 , ou $31,9 \%)$.

É importante perceber que o período predominantemente crítico às que questionavam a eficácia do modelo adotado na região durante quase duas décadas, de forma a reportar o estado de ânimo da região ao resto das Américas:

In each of Brazil's last two presidential elections, Ana Paula Borges voted for the government's candidate, swayed by promises of growth and stability. But after an eight-year experiment with free-market capitalism, the Brazilian economy has stalled, unemployment is climbing, the value of the national currency is sliding, and she is fed up. [...] All over Latin

Gráfico 5. Posicionamento (crítico, favorável ou equilibrado) sobre neoliberalismo, a cada ano.

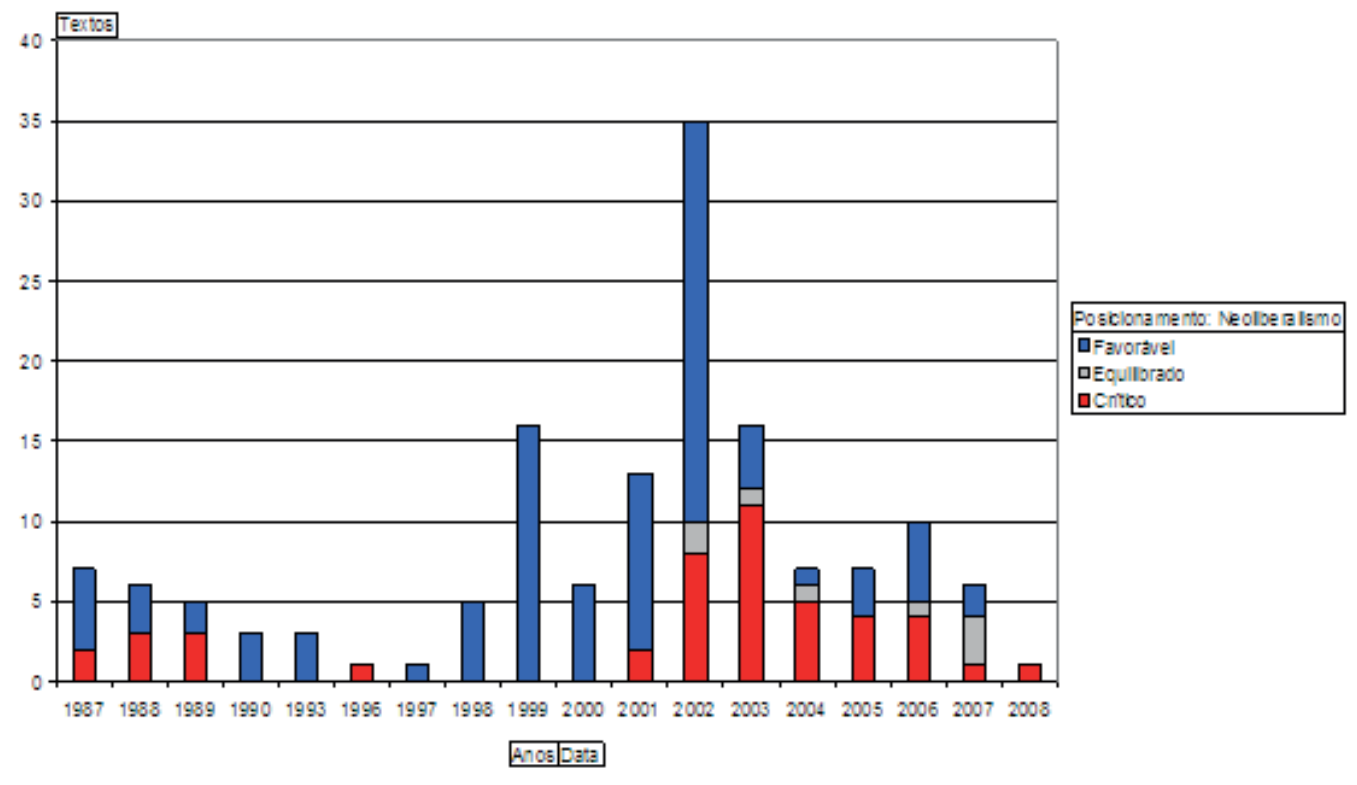

medidas neoliberais é próximo, porém ligeiramente posterior, ao avanço das comparações brasileiras positivas a partir de 1998 (Gráfico 3). Isso sugere que muitos dos elogios econômicos brasileiros eram dados com o pano de fundo de transformações no ideário comercial e, portanto, apontavam para um caminho transitório, ao mesmo tempo crítico às receitas antigas no discurso, mas ainda flexível, nas ações, ao continuar adotando muitas das medidas valorizadas anteriormente. Esse período mais crítico também é concomitante com a eleição de diversos líderes de esquerda na América Latina; pode-se dizer que Rohter deixaria transparecer, em suas reportagens, as críticas de líderes e eleitores latino-americanos
America, candidates critical of the Washington Consensus, the name often used to describe the Americanbacked free-market model common in the region since the 1990's, are watching from the wings as governments committed to such reforms flounder. That sentiment has been fed by the collapse of the Argentine economy and by similar crises in countries ranging from Uruguay to Venezuela. ${ }^{13}$

O trecho apresenta uma crítica radical, contrapondo as expectativas e promessas (que, subentende-se, não foram cumpridas) de "crescimento e estabilidade" durante oito anos de "experimento com o capitalismo de livre-mercado", com uma realidade DOI: 10.5007/1984-6924.2016v13n1p131 públicos"”.
${ }^{13}$ ROHTER, Larry. "In Free-Market Slump, Brazil's Voters Look for Change". NYT, 05/10/2002. Tradução do autor: "Nas duas últimas eleições presidenciais brasileiras, Ana Paula Borges votou no candidato do governo, envolvida por promessas de crescimento e estabilidade. Mas após um experimento de oito anos com o capitalismo de livre-mercado, a economia brasileira está estagnada, o desemprego está crescendo, o valor do câmbio está despencando, e ela está cansada. (...) Em toda a América Latina, candidatos críticos ao Consenso de Washington, o nome frequentemente usado para descrever o apoio americano de um modelo comum de mercados livres na região desde os anos 1990, estão aproveitando enquanto os governos comprometidos com essas reformas afundam. Esse sentimento tem sido alimentado pelo colapso da economia argentina e por crises similares em países como o Uruguai e a Venezuela".

ROHTER, Larry. "Lawmakers In Brazil Adopt Step On Austerity". NYT, 21/01/1999. Tradução do autor: "Em um importante avanço no esforço do governo em cortar seu déficit e reduzir as pressões do mercado que tem atormentado a economia, a câmara dos deputados nessa noite aprovou uma mudança decisiva nos benefícios de segurança social para servidores públicos depois de quatro tentativas anteriores terem sido derrotadas. (...) Mas oponentes acusaram FHC de vender o Brasil, que tem a maior economia na América Latina, e seus 165 milhões de habitantes para o FMI e bancos e investidores americanos. 'O que o governo está pedindo para acalmar os mercados é o sangue dos servidores', disse Walter Pinheiro, um líder do Partido dos Trabalhadores, o principal partido de oposição. 'Para agradar investidores estão nos pedindo para massacrar os aposentados e os funcionários 
${ }^{14}$ ROHTER, Larry. "Lawmakers In Brazil Adopt Step On Austerity”. NYT, 21/01/1999.

Tradução do autor: "Em um importante avanço no esforço do governo em cortar seu déficit e reduzir as pressões do mercado que tem atormentado a economia, a câmara dos deputados nessa noite aprovou uma mudança decisiva nos benefícios de segurança social para servidores públicos depois de quatro tentativas anteriores terem sido derrotadas. (...) Mas oponentes acusaram FHC de vender o Brasil, que tem a maior economia na América Latina, e seus 165 milhões de habitantes para o FMI e bancos e investidores americanos. 'O que o governo está pedindo para acalmar os mercados é o sangue dos servidores', disse Walter Pinheiro, um líder do Partido dos Trabalhadores, $o$ principal partido de oposição. 'Para agradar investidores estão nos pedindo para massacrar os aposentados e os funcionários públicos"”. de desaquecimento econômico com o "desemprego crescendo, o valor da moeda nacional escorregando", o que levou eleitores como a citada na reportagem a desistirem do modelo. Essa tendência ecoa na representação dos líderes da esquerda latinoamericana que aproveitam a queda dos governos que se comprometeram às "reformas" que seguem o "Consenso de Washington". Rohter até apresenta o sentido dessa expressão, "como o nome frequentemente usado para descrever o modelo de abertura dos mercados", frisando o "apoio" norte-americano na questão.

\section{Conclusão}

$\mathrm{O}$ foco negativo assumido pelo correspondente na crítica acima destoa dos períodos anteriores, mesmo considerando momentos de crise, quando havia espaço para declarações contestatórias de fontes retoricamente ainda mais descontentes do que a eleitora acima:

In an important advance in the Government's effort to cut its deficit and reduce market pressures that have humbled the economy, the lower house of Congress tonight decisively approved a change in social security benefits for civil servants after four earlier attempts had been defeated. (...)

But opponents accused Mr. Cardoso of selling out Brazil, which has the largest economy in Latin America, and its 165 million people to the I.M.F. and American banks and investors.

"What the Government has asked for to calm the markets is the blood of civil servants," said Walter Pinheiro, a leader of the Workers' Party, the main opposition party. 'To please investors we are being asked to massacre retirees and government employees." ${ }^{14}$
Essa reportagem, publicada durante a crise da desvalorização do real em 1999, apresenta pontos divergentes, mostrando também críticas às práticas liberais (como a flexibilização cambial) e a austeridade fiscal, representada no argumento emotivo do líder petista que critica o sacrifício do "sangue" e o massacre de "aposentados e funcionários públicos”. Porém, para além das fontes e dos argumentos acalorados, a introdução do correspondente ainda valoriza como um "avanço importante" o "esforço para cortar o déficit", deixando claro que as medidas do governo brasileiro estavam em sintonia com "as pressões do mercado" e, também, com a avaliação do correspondente do jornal - as críticas, no trecho, permanecem encurraladas na fala dos "opositores", e somente por eles são validadas.

Já em momentos recentes, a crítica de Rohter parece ter adotado uma característica mais analítica, pesando não só os pontos negativos e positivos das medidas liberais, mas também explicando o conceito em mais profundidade:

At the outset of the 1990's, “The Washington Consensus" - the name given to the recipe of open markets, privatization and stabilized budgets being pushed by the United States - seemed to have swept away everything before it. Voters were pleased to see inflation, a traditional bugaboo in the region, quickly brought under control and looked forward to other gains.

But over the past decade, freer trade and increased foreign investment have failed to narrow the gap between rich and poor and left millions of poor people outside the economy and looking in resentfully. Between 1998 and 2003 , once inflation is taken into account, Latin America as a whole did not grow at all, according to International Monetary Fund figures. ${ }^{15}$ 
Em primeiro lugar, o texto usa uma terminologia mais forte para explicar a origem do "consenso", apontando que essa "receita" foi "empurrada pelos Estados Unidos”, e não somente "apoiada", como descrito no texto anteriormente analisado ${ }^{16}$. O trecho também apresenta uma das descrições mais completas do receituário liberal entre as publicadas por Rohter: vai além do conceito neutro de "abertura dos mercados" para tratar de temas mais polêmicos - e que convenientemente ficavam de fora de seus relatos anteriores - como a "privatização". Entretanto, outros ingredientes aparecem de forma opaca e indireta, como a "estabilidade de orçamentos" que se refere, supostamente, ao congelamento dos gastos governamentais, a manutenção de altos superávits e a diminuição do endividamento do Estado. Também os benefícios liberais são diretamente contestados, ao mostrar o desapontamento dos que aguardavam outros "ganhos" além do controle do

\section{Referências}

CRESPO, Sílvio Guedes. "Imprensa estrangeira destaca Brasil como ator internacional". Radar Econômico, 26 de abril de 2010.

DOTA, Maria Inez Mateus. "Aspectos Econômicos do Brasil: o Discurso do New York Times". In: Anais do XXVII Congresso Brasileiro de Ciências da Comunicação, 2004, Porto Alegre. São Paulo: Intercom, 2004.

GROSECLOSE, Tim; MILYO, Jeff. A Measure of Media Bias. Los Angeles, UCLA, Dez. 2004. Disponível em: http://www.sscnet.ucla.edu/polisci/faculty/groseclose/ Media.Bias.8.htm

HABERMAS, Jürgen. Mudança Estrutural da Esfera Pública. Rio de Janeiro: Tempo Brasileiro, 2003.

HERMAN, Edward. "All The News Fit To Print (Part I): Structure and Background of the New York Times”. Z magazine, Abr. 1998.

HERMAN, Edward; MCCHESNEY, Robert. The Global Media: The new Missionaries of Corporate Capitalism. Nova Déli: Madhyam Books, 1998.

HIGGINS, Vanessa de Macedo. "Foreign perspectives of Brazil: A textual analysis of American newspaper coverage". Brazilian Journalism Research, Vol. 2, N. 1, p. 175193, 1 Semestre de 2006.
15 ROHTER, Larry. "With New Chief, Uruguay Veers Left, in a Latin Pattern". NYT, 01/03/2005. Tradução do autor: "No começo dos anos 1990, o 'Consenso de Washington' - o nome dado à receita de abertura de mercados, privatizações e estabilização orçamentária que tem sido empurrada pelos EUA - parecia ter apagado tudo que viera antes. Os eleitores estavam satisfeitos em ver a inflação, um tradicional bicho-papão da região, rapidamente ser controlada e esperaram outros ganhos futuros. Mas após a última década, o comércio mais livre e o aumento do investimento estrangeiro falharam em diminuir a distância entre ricos e pobres e deixaram milhões de pobres fora da economia, olhando com ressentimento. Entre 1998 e 2003, considerando a inflação, a América Latina como um todo não cresceu nem um pouco, de acordo com dados do Fundo Monetário Internacional".

${ }^{16}$ ROHTER, Larry. "In Free-Market Slump, Brazil's Voters Look for Change". NYT, 05/10/2002. 
HOLANDA, Sérgio Buarque. Visão do Paraíso. São Paulo: Brasiliense, 2007.

KUCINSKI, Bernardo. Jornalismo econômico. São Paulo: Edusp, 2000.

OKRENT, Daniel. "THE PUBLIC EDITOR; Is The New York Times a Liberal Newspaper?”. The New York Times, 25 jul. 2004.

PRATT, Mary Louise. Os olhos do império: relatos de viagem e transculturação. Bauru: Edusc, 1999.

RASMUSSEN REPORTS. "New York Times, Washington Post, and Local Newspapers Seen as Having Liberal Bias". Rasmussen Reports, 15 jul. 2007.

SODRÉ, Muniz. A narração do fato: notas para uma teoria do acontecimento. Petrópolis: Vozes, 2009.

WILLIAMSON, John. “The Washington Consensus Revisited”. In: EMMERIJ, Louis (org). Economic and social development into the XXI Century. Washington: InterAmerican Development Bank, 1997. 